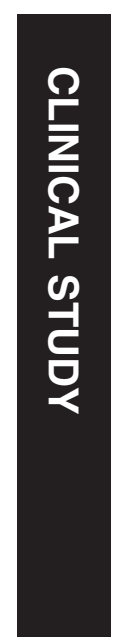

${ }^{1}$ Pediatric Ophthalmology and Strabismus

Department, Professor Dr N. Reşat Belger Beyoglu Education and Research Eye Hospital, Istanbul, Turkey

${ }^{2}$ Faculty of Medicine, Ophthalmology

Department, Pamukkale

University, Denizli, Turkey

${ }^{3}$ Professor Dr N. Reşat Belger Beyoglu Education and Research Eye Hospital, Istanbul, Turkey

Correspondence:

S Akar, Pediatric Ophthalmology and Strabismus Department, Professor Dr N. Reşat Belger Beyoglu Education and Research Eye Hospital, Acibadem cad, Yurtsever sok., Alsancak sitesi, E Blk, Da:19 Acibadem/Kadikoy, Istanbul 34718, Turkey. Tel: + 902163274787 ; Fax: +90212 2450947 E-mail:akarserpil@ yahoo.com

Institution at which the study was conducted: Professor Dr N. Reşat Belger Beyoglu Education and Research Eye Hospital, Istanbul, Turkey.

Received: 25 February 2013 Accepted in revised form: 4 July 2013

Published online: 2 August 2013

\section{Vertical muscle transposition augmented with lateral fixation (Foster) suture for Duane syndrome and sixth nerve palsy}

\begin{abstract}
Purpose To report the postoperative results of full-tendon vertical rectus transposition (VRT) augmented with lateral fixation suture for the treatment of type 1 Duane syndrome and sixth nerve palsy and to determine whether there was a decrease in the effect of the Foster suture over time.

Methods This retrospective, consecutive case series included patients who underwent a full-tendon VRT transposition with lateral fixation for type 1 Duane syndrome or sixth nerve palsy. The primary outcome measures included deviation, abnormal head posture (AHP), abduction deficiency, and postoperative binocular single visual field (BSVF).
\end{abstract}

Results Eighty-seven patients (87 eyes: 40 eyes with Duane syndrome and 47 eyes with sixth nerve palsy) were included in this study. In Duane syndrome patients, the deviation was reduced by a mean of $95 \%$, the AHP was eliminated in $86 \%$ of patients, the abduction was improved by $42 \%$, and a useful BSVF of $\sim 67 \%$ of normal was achieved at 1 year post operation. In sixth nerve palsy patients, the deviation was reduced by $99 \%$, the abduction was improved by $59 \%$, and a useful BSVF of $\sim 71 \%$ of normal was achieved at 1 year post operation. In both groups, the improvements in deviation angle and abduction were stable postoperatively. Sixteen patients needed reoperation for undercorrection.

Conclusion VRT surgery with posterior fixation is an effective treatment method for complete sixth nerve palsy and Duane syndrome with esotropia, AHP, and
S Akar ${ }^{1}$, B Gokyigit ${ }^{1}$, G Pekel $^{2}$, A Demircan $^{3}$ and A Demirok ${ }^{3}$ abduction deficiency. The procedure carries a small risk of reoperation for undercorrection. The effect of the Foster suture did not decline over time.

Eye (2013) 27, 1188-1195; doi:10.1038/eye.2013.167; published online 2 August 2013

Keywords: type 1 Duane retraction syndrome; palsies; sixth nerve; ophthalmologic surgical procedures

\section{Introduction}

Vertical rectus transposition (VRT) surgery was first described by Hummelsheim in 1907 for the treatment of lateral rectus (LR) muscle palsies. ${ }^{1}$ Later, several authors recommended full-tendon VRT over other forms of treatment for LR muscle palsies, ${ }^{1-4}$ as well as for type 1 Duane syndrome with esotropia and a face turn in the primary position. ${ }^{5,6}$ In 1997, Foster ${ }^{7}$ described the modification of posterior augmentation of full-tendon VRT using nonabsorbable sutures to enhance the lateralization of each transposed rectus muscle. This procedure improved the primary position alignment and abduction without the need for an ipsilateral medial rectus (MR) muscle recession, thus minimizing the disruption of the anterior segment circulation. $^{7}$

The purpose of this study is to evaluate the postoperative results of full-tendon VRT augmented with a lateral fixation (Foster) suture for the treatment of esotropic Duane syndrome and sixth nerve palsy and determine whether there was a decrease in the effect of the Foster suture over time. 


\section{Materials and methods}

After obtaining approval from the Ethics Committee and the Institutional Review Board at the Professor Dr N. Reşat Belger Beyoglu Education and Research Eye Hospital, Istanbul, Turkey, the medical records of 87 consecutive patients who underwent full-tendon VRT augmented with Foster suture for the treatment of sixth nerve palsy or esotropic Duane syndrome between March 1994 and February 2012 were reviewed. Included in this study were patients who had unilateral type 1 Duane syndrome with esotropia $\geq 25$ pd in the primary position, an abnormal head posture (AHP) $\geq 25$ degrees, full or minimally limited adduction, and no significant upshoots or downshoots in the adducted position. The included sixth nerve palsy patients had unilateral, chronic, complete sixth nerve palsy with no abducting force on forced generation testing, a stable ocular deviation angle for at least three consecutive visits, a time period lasting at least 6 months between the onset of palsy and the operation, and follow-up of at least 12 months. The exclusion criteria included bilateral disorders, incomplete palsy, or mechanical limitations of eye abduction, such as contracture, fibrosis, convergent strabismus fixus, myositis, endocrine orbitopathy, a history of previous extraocular muscle surgery, or any other associated ocular pathology that could limit adequate examination. The study and the data collection conformed to all local laws and were compliant with the principles of the Declaration of Helsinki. Informed consent was obtained from each participant; for children younger than 18 years of age, consent was obtained from one or both of the parents.

Before surgical intervention, all patients received complete ophthalmic and orthoptic examinations, including assessment of AHP and measurement of ocular deviation in the primary position and in the diagnostic gaze positions. The angle of deviation in the primary position at 20 feet was measured by a cover test, with the involved eye fixing on a distant target. The correcting prism was always placed in front of the paretic eye to measure the primary deviation. The AHP in degrees corresponded to the angle formed by the axial axis of the skull and an imaginary line perpendicular to the transverse axis of the body. The AHP was qualitatively estimated for all patients while the patient sat erect, fixating on a target 20 feet distant as previously described. ${ }^{5,8}$

Ocular versions and ductions were recorded on a 6-point scale as follows: $0=$ full movement, $-1=$ restriction to $45^{\circ}$ of abduction, $-2=$ movement limited to $30^{\circ},-3=$ movement limited to $15^{\circ}$, $-4=$ unable to move the eye past the midline, and $-5=$ unable to rotate the eye to the midline. ${ }^{9}$ We used the muscle force generation test to measure the force generated during attempted maximal abduction with the eye being held in extreme adduction and recorded on a scale of -4 (no force generated) to 0 (normal force generated). ${ }^{10}$ This test determines whether the paralysis is complete or incomplete. We use forced duction testing to measure the restriction to positive stretching of the antagonist MR muscle and recorded this restriction on a scale of 0 (no restriction) to -4 (an inability to move the eye into the abducting field). ${ }^{10}$ This test was performed pre- and intraoperatively to determine the presence of contracture of the MR.

The Goldmann visual field perimeter was used to measure the extent of the postoperative diplopia-free field. The patient's head was positioned in the perimeter in line with the fixation target and in forced primary position, and the field of single binocular vision was tested with the use of a $15-\mathrm{mm}$ white target. ${ }^{11}$

The examinations were performed 1 week before surgery and were repeated postoperatively at 1, 3, 6, and 12 months; thereafter, examinations were performed on an annual basis.

The surgical approach followed the previous description by Foster. ${ }^{7}$ The superior rectus (SR) and inferior rectus (IR) muscles (including the full tendon and muscle bellies) were transposed to the corresponding superior or inferior border of the LR muscle following the Spiral of Tillaux. The temporal borders of the SR muscle and the IR muscle were attached to the sclera immediately adjacent to the respective border of the LR muscle. The nasal borders of the transposed muscles were inserted in the sclera following the spiral of Tillaux, at a distance from the limbus to the medial border of the transposed muscles equivalent to the original insertion distance. Two 5-0 nonabsorbable polyester sutures (Dacron; Ethicon Inc. Somerville, NJ, USA) were placed through the sclera $8 \mathrm{~mm}$ posterior to the insertion of the LR muscle, fixing the belly of each transposed muscle adjacent to the border of the LR muscle (Figure 1). 7,8

In patients who underwent undercorrection following augmented VRT, we performed Botulinum toxin A (Botox, Allergan Inc., Irvine, CA, USA) injection of the ipsilateral MR muscle 1-2 weeks following the transposition surgery and/or a subsequent recession of the ipsilateral or contralateral MR muscle 4-6 months later. When we operated on three rectus muscles, we preserved 1-2 anterior ciliary vessels.

Data were analyzed using SPSS for Windows, version 16 (SPSS Inc., Chicago, IL, USA). The descriptive statistics, frequencies and percentages of categorical variables, and the means and standard deviations of numeric variables were calculated. The $\chi^{2}$-test was used for the comparison of the categorical variables between 


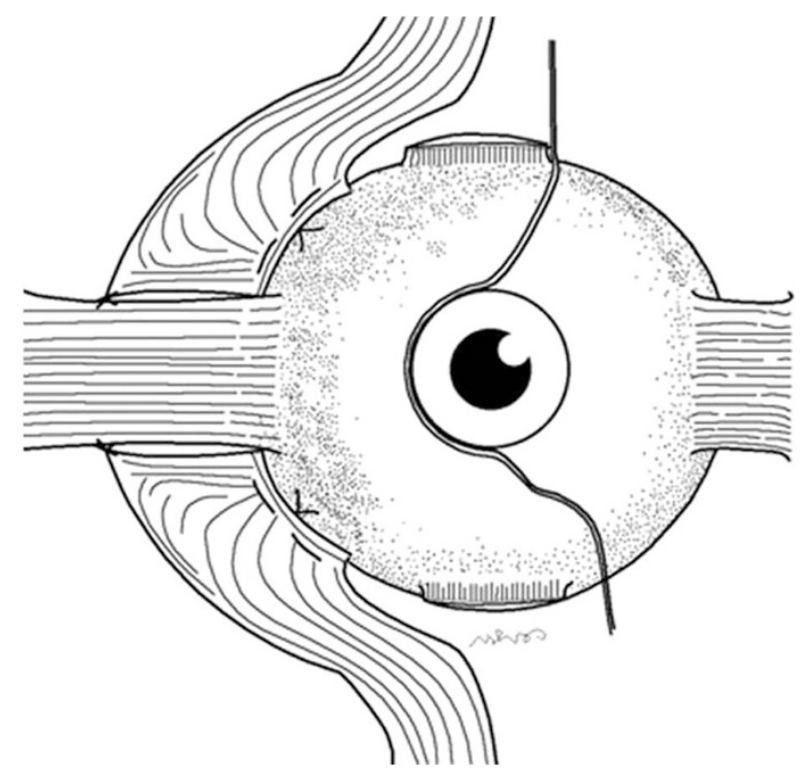

Figure 1 Schematic drawing of the augmented muscle transposition procedure. The superior rectus and inferior rectus muscles (including the full tendon and muscle bellies) were transposed to the corresponding superior or inferior border of the LR muscle following the Spiral of Tillaux. Two 5-0 nonabsorbable polyester sutures were placed through the sclera $8 \mathrm{~mm}$ posterior to the insertion of the LR muscle, fixing the belly of each transposed muscle adjacent to the border of the LR muscle.

groups. The Shapiro-Wilk test was used to evaluate the normality of distributions. Differences between preoperative and first-postoperative-year values and differences between the first postoperative month and the final examination (mean 38 months) values were compared. The paired sample $t$-test was used for normally distributed variables, and the Wilcoxon signed rank test and Mann-Whitney test were used for non-normally distributed variables. In patients who underwent only VRT surgery augmented with Foster suture, the Friedman test was used for differences between the preoperative assessment and postoperative assessment during months 1 and 6 or years 1,2,3, and 4, and Dunn's test was used for simultaneous estimation of all pairwise comparisons of postoperative values. Little's missing completely at random test was used to test the randomness of missing data. Values of $P<0.05$ were considered statistically significant.

\section{Results}

Forty of the 87 patients had unilateral esotropic type 1 Duane syndrome, and 47 patients had unilateral chronic complete sixth nerve palsy. Eighty-seven patients had unilateral full-tendon VRT augmented with posterior fixation sutures. Sixteen patients needed reoperation for undercorrection. Six of 16 patients had a diagnosis of Duane syndrome and 10 patients had a diagnosis of sixth nerve palsy. In undercorrected cases, ipsilateral or contralateral MR recession was performed 4-6 months after the augmented transposition surgery.

Pre- and postoperative data on age, gender, the AHP, the angle of esotropia, abduction, adduction, force duction test, total binocular single visual field (BSVF), complications, and follow-up period for the two groups are summarized in Table 1 . The pre- and postoperative deviation angle and abduction changes for patients who underwent only VRT surgery augmented with Foster suture for Duane syndrome or sixth nerve palsy are shown in Table 2.

In the Duane syndrome group, a statistically significant difference was found between preoperative and the first-postoperative-year values in relation to the AHP, the angle of esotropia, and abduction $(P \leq 0.001$ for each comparison) (Table 1). No significant differences were found between the first postoperative month and the final examination in relation to the angle of esotropia and abduction ( $P>0.05$ for each comparison). No significant differences were found between months 1 and 6 or years $1,2,3$, and 4 postoperatively, which reflects the stability of improvements in the angle of esotropia and in abduction after surgery ( $P>0.05$ for each comparison) (Table 2).

In the sixth nerve palsy group, there was a statistically significant difference between preoperative and the firstpostoperative-year values in relation to the AHP, the angle of esotropia, abduction, and force abduction ( $P \leq 0.001$ for each comparison) (Table 1 ). No significant differences were found between the first postoperative month and the final examination in terms of the angle of esotropia and abduction ( $P>0.05$ for each comparison). No significant differences were found between months 1 and 6 or years 1, 2, 3, and 4 postoperatively, thus confirming the stability of the angle of esotropia and abduction after surgery $(P>0.05$ for each comparison) (Table 2).

Missing data met the missing completely at random assumption according to Little's missing completely at random test results in both groups $(P=0.080$ and 0.980 for the Duane type I and the sixth nerve palsy groups, respectively). As the missing completely at random assumption was satisfied, complete case methods gave unbiased estimates. Also, there was no difference between the values of patients who were lost to followup and those who were not lost to follow-up in the first postoperative year (all observations were complete at that time) as well as in years 2, 3, and 4 postoperatively.

No patients in the Duane Syndrome group or in the sixth nerve palsy group had preoperative BSVFs; however, all patients had Lee's screening test pre- and 
Table 1 Pre- and postoperative data from patients with Duane syndrome and sixth nerve palsy who underwent vertical rectus muscle transpositions augmented with Foster posterior fixation sutures

\begin{tabular}{|c|c|c|}
\hline & Duane syndrome & Sixth nerve palsy \\
\hline $\begin{array}{l}\text { No. of patients } \\
\text { Age (yr) } \\
\text { Gender (M/F) }\end{array}$ & $\begin{array}{c}40 \\
11.35 \pm 9.6(4-39) \\
16 / 24\end{array}$ & $\begin{array}{c}47 \\
37.05 \pm 23.02(4-78) \\
24 / 23\end{array}$ \\
\hline $\begin{array}{l}\text { Abnormal head posture } \\
\text { Pre-op } \\
\text { Post-op } \\
\% \text { change } \\
P \text {-value }\end{array}$ & $\begin{aligned} 27.5 & \pm 3.4(20-30) \\
3.8 & \pm 2.4(0-10) \\
& 86 \% \\
\leq & 0.001\end{aligned}$ & $\begin{array}{c}25.0 \pm 4.6(20-30) \\
1.8 \pm 3.3(0-10) \\
92 \% \\
\leq 0.001\end{array}$ \\
\hline $\begin{array}{l}\text { The angle of esotropia } \\
\text { Pre-op } \\
\text { Post-op } \\
\% \text { change } \\
P \text {-value }\end{array}$ & $\begin{array}{l}32 \pm 9.6(25-60) \\
2.1 \pm 5.4(8-20) \\
95 \% \\
\leq 0.001\end{array}$ & $\begin{array}{c}42.2 \pm 14.1(18-60) \\
0.9 \pm 6.4(0-14) \\
99 \% \\
\leq 0.001\end{array}$ \\
\hline $\begin{array}{l}\text { Abduction } \\
\text { Pre-op } \\
\text { Post-op } \\
\% \text { change } \\
P \text {-value }\end{array}$ & $\begin{array}{l}-3.8 \pm 0.4(3-4) \\
-2.2 \pm 0.6(1-3) \\
\quad 42 \% \\
\leq 0.001\end{array}$ & $\begin{array}{l}-3.9 \pm 0.4(4-5) \\
-1.6 \pm 0.8(1-3) \\
59 \% \\
\leq 0.001\end{array}$ \\
\hline $\begin{array}{l}\text { Adduction } \\
\text { Pre-op } \\
\text { Post-op } \\
P \text {-value }\end{array}$ & $\begin{array}{c}-0.48 \pm 0.03(0-1) \\
-0.50 \pm 0.1(0-1) \\
0.987\end{array}$ & $\begin{array}{l}0.0 \\
0.0 \\
-\end{array}$ \\
\hline $\begin{array}{l}\text { Forced duction test (abduction) } \\
\text { Intra-op }\end{array}$ & $-1.4 \pm 0.5$ & $-2.8 \pm 0.4$ \\
\hline $\begin{array}{l}\text { Postop BSVF } \\
\text { No. of measurable patients, } n(\%) \\
\text { Abduction BSVF }\left({ }^{\circ}\right) \\
\text { Total BSVF }\left({ }^{\circ}\right)\end{array}$ & $\begin{array}{c}28(70 \%) \\
21 \pm 3.7(15-25) \\
67.20 \pm 16.4(35-90)\end{array}$ & $\begin{array}{c}38(81 \%) \\
24 \pm 5.6(15-28) \\
71.05 \pm 17.2(30-90)\end{array}$ \\
\hline $\begin{array}{l}\text { Complications } \\
\text { Undercorrection, } n(\%) \\
\text { Overcorrection } \\
\text { Vertical deviation, }{ }^{\text {b }} n(\%) \\
\text { Anterior segment ischemia, } n(\%) \\
\text { Lid fissures narrowing, } n(\%)\end{array}$ & $\begin{array}{l}6(15 \%) \\
0(0 \%) \\
4(10 \%) \\
0(0 \%) \\
0(0 \%)\end{array}$ & $\begin{aligned} & 10(21 \%) \\
& 0(0 \%) \\
& 3(6 \%) \\
& 0(0 \%) \\
& 0(0 \%)\end{aligned}$ \\
\hline $\begin{array}{l}\text { Additional attempt } \\
\text { Pre-op Botulinum toxin } \mathrm{A}_{,}^{\mathrm{c}} n(\%) \\
\text { Post-op Botulinum toxin A, }{ }^{\mathrm{d}} n(\%) \\
\text { Secondary surgery, } n(\%) \\
\text { Follow-up period (mo) }\end{array}$ & $\begin{array}{c}0(0 \%) \\
4(10 \%) \\
6(15 \%) \\
37.8 \pm 13.07(12-48)\end{array}$ & $\begin{array}{c}28(60 \%) \\
2(4 \%) \\
10(21 \%) \\
37.09 \pm 14.3(12-72)\end{array}$ \\
\hline
\end{tabular}

Abbreviations: BSVF, binocular single visual field; intra-op, intraoperative; mo, months; $\mathrm{M} / \mathrm{F}$, male/female; No., number; pre-op, preoperative; post-op, postoperative; $\mathrm{Yr}$, year.

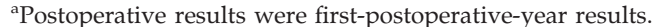

${ }^{\mathrm{b}}$ All patients had $\leq 4 \mathrm{pd}$ angle-induced vertical deviation, but none required surgery.

'Twenty-eight patients who had sixth nerve palsy underwent Botulinum toxin injections into the ipsilateral medial rectus muscle during the waiting period before surgery.

${ }^{\mathrm{d}}$ In undercorrected cases, injection of the Botulinum toxin $\mathrm{A}$ in the ipsilateral MR muscle was performed 1-2 weeks after surgery.

'In undercorrected cases, ipsilateral or contralateral MR recession was performed 4-6 months after the augmented transposition surgery. In the Duane's syndrome group, five of the six patients who required further MR recession had -3 or -4 restriction to abduction on the intraoperative force duction test. In the sixth nerve palsy group, 9 of the 10 patients who required further MR recession had -4 restriction to abduction on the intraoperative force duction test.

postoperatively. We cannot compare the BSVFs between the two groups, because the number of patients who had preoperative BSVFs was insufficient.

Abduction was improved by $59 \%$ in patients with sixth nerve palsy and by a significantly smaller $42 \%$ in patients with Duane syndrome $(P=0.015)$.
Table 2 The pre- and postoperative data of patients who underwent only vertical rectus transposition surgery augmented with Foster suture for Duane syndrome or sixth nerve palsy, with their distribution according to the time of the postoperative data collection

\begin{tabular}{|c|c|c|c|c|c|c|}
\hline & \multicolumn{3}{|c|}{ Duane syndrome } & \multicolumn{3}{|c|}{ Sixth nerve palsy } \\
\hline & $\begin{array}{l}\text { No. of } \\
\text { patients } \\
(n)\end{array}$ & $\begin{array}{l}\text { Mean } \\
\text { esotropia } \\
\text { (pd) }\end{array}$ & $\begin{array}{c}\text { Mean } \\
\text { abduction }\end{array}$ & $\begin{array}{l}\text { No. of } \\
\text { patients } \\
(n)\end{array}$ & $\begin{array}{c}\text { Mean } \\
\text { esotropia } \\
(p d)\end{array}$ & $\begin{array}{c}\text { Mean } \\
\text { abduction }\end{array}$ \\
\hline Pre-op & 34 & $29.8 \pm 8.3$ & $-3.8 \pm 0.4$ & 37 & $42.05 \pm 7.4$ & $-3.9 \pm 0.4$ \\
\hline \multicolumn{7}{|l|}{ Post-op } \\
\hline 1 month & 34 & $0.74 \pm 0.1$ & $-2.2 \pm 0.1$ & 37 & $0.95 \pm 0.07$ & $-1.8 \pm 0.7$ \\
\hline 6 months & 34 & $1.47 \pm 0.4$ & $-2.2 \pm 0.06$ & 37 & $0.10 \pm 0.03$ & $-1.8 \pm 0.1$ \\
\hline 1 year & 34 & $1.31 \pm 0.3$ & $-2.2 \pm 0.3$ & 37 & $0.57 \pm 0.01$ & $-1.6 \pm 0.9$ \\
\hline 2 years & 27 & $0.40 \pm 0.03$ & $-2.1 \pm 0.8$ & 32 & $0.60 \pm 0.02$ & $-1.7 \pm 0.3$ \\
\hline 3 years & 21 & $1.62 \pm 0.08$ & $-2.3 \pm 0.4$ & 26 & $0.65 \pm 0.04$ & $-1.8 \pm 0.4$ \\
\hline 4 years & 16 & $1.01 \pm 0.2$ & $-2.5 \pm 0.5$ & 22 & $0.71 \pm 0.08$ & $-1.7 \pm 0.6$ \\
\hline
\end{tabular}

Abbreviations: No., number; pd, prism diopter; post-op, postoperative; pre-op, preoperative.

Figures 2A and B show pre- and postoperative photographs of one case with left type 1 Duane syndrome and pre- and postoperative photographs of one case with sixth nerve palsy, respectively.

\section{Discussion}

Foster reported that the addition of lateral fixation sutures to full VRT improved the resulting tonic abducting force for patients with LR palsy or type 1 Duane syndrome. ${ }^{7}$ The augmented transposition seems to be effective even in the presence of MR restriction. ${ }^{1,4}$ Rosenbaum ${ }^{1}$ and Velez et $a l^{8}$ reported that if the MR demonstrates significant contracture, additional therapy such as Botox injection or recession of the ipsilateral or contralateral MR muscles will be required to obtain optimal results. ${ }^{2,4}$ In accordance with previous reports, we first performed the augmented transposition procedure, and later, if needed, this was followed by Botulinum toxin injection and/or recession of the MR muscle. The patients who required further MR recession and/or Botulinum toxin injections had marked restriction to abduction on the intraoperative force duction test.

Some authors have suggested that VRT surgery with posterior fixation should be performed for type 1 Duane syndrome patients with esotropia of $20 \mathrm{pd}$ or more, an AHP larger than $20^{\circ}$, limited abduction, and no significant upshoots or downshoots in the adducted position. ${ }^{1,4}$ We used this rule in our series. In some studies where type 1 Duane syndrome was treated with augmented transposition surgery, the deviation was reduced by $75-85 \%$, the AHP was reduced by $80-83 \%$, the abduction improved in $97-100 \%$ of patients with a change of $26-29 \%$, and the binocular visual field 

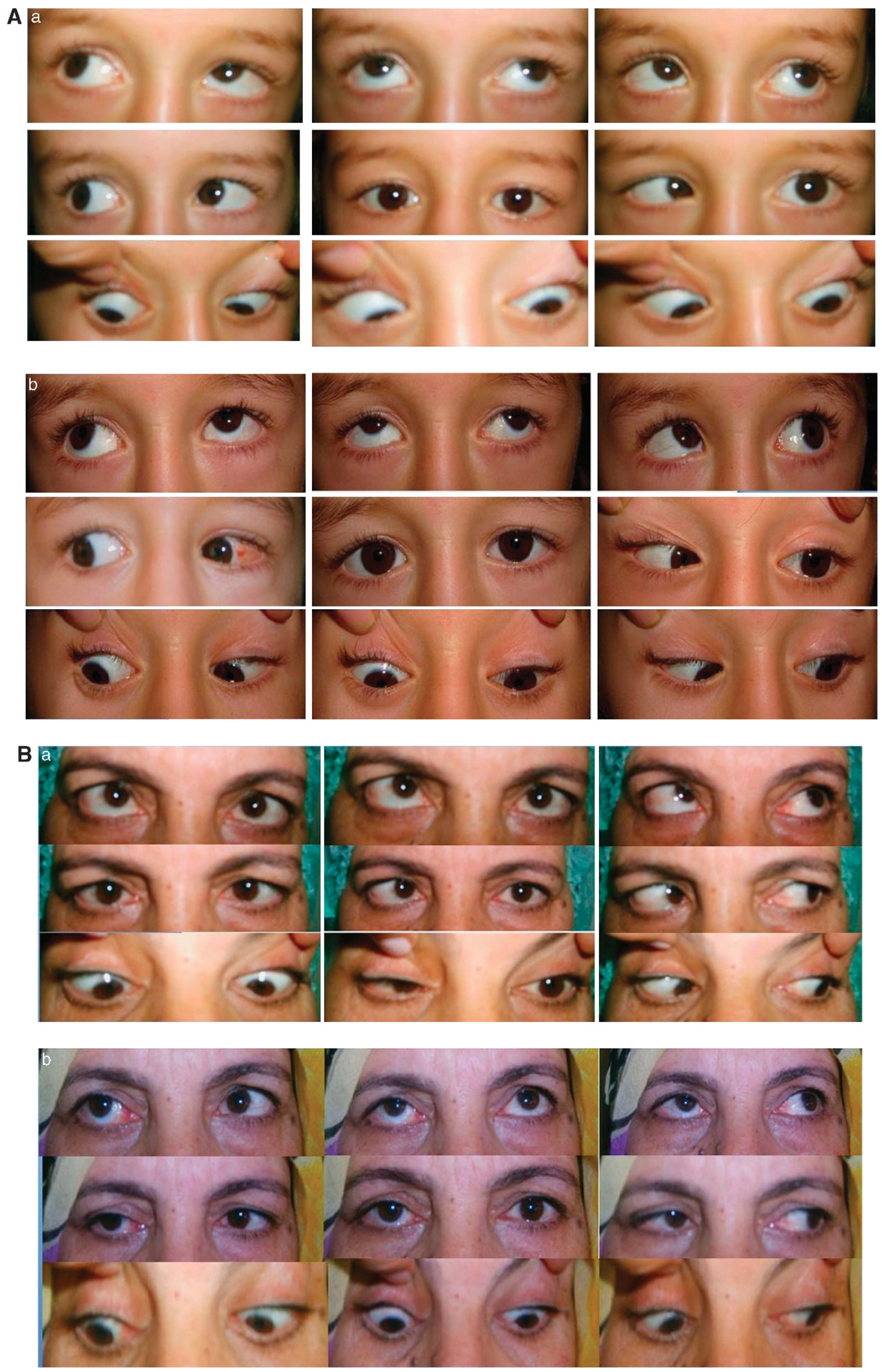

Figure 2 (A) (a) Preoperative photographs of a case with left type 1 Duane syndrome. (b) Postoperative photographs showing nine positions of the gaze 1 month after surgery. Eye position and abduction improved. (B) (a) Preoperative photographs of a case with right sixth nerve palsy. (b) Postoperative photographs showing nine positions of the gaze 6 months after surgery. Eye position and abduction markedly improved. 
was enlarged up to $20-67^{\circ}$ with no loss of adduction postoperatively. ${ }^{1,7-9}$ Our outcomes are consistent with those previously reported. The mean reduction in deviation was $95 \%$, the AHP was reduced by $86 \%$, the abduction improved in $100 \%$ of patients with a mean change of $42 \%$, and a useful BSVF of $\sim 67 \%$ of normal was achieved with no loss of adduction for type 1 Duane syndrome cases following augmented transposition surgery. The postoperative deviation angles and abductions were stable for the duration of the follow-up.

Foster ${ }^{7}$ reported that VRT surgery with posterior fixation could be performed in patients with LR palsy who demonstrated no abducting force on force generation testing and showed 'floating' abducting saccades. As reported by Foster, ${ }^{7}$ we performed augmented transposition surgery on patients with complete palsy, who demonstrated no abducting force on force generation testing. Some authors reported results of patients who had undergone full-tendon augmented transposition surgery for LR palsy. $7,12,13$ In these studies, the mean correction of deviation was $30-42 \mathrm{pd}$, and the abduction deficiency improved in all patients with a change of $20-50 \%$, and $0-29 \%$ of patients had AHP postoperatively. ${ }^{7,12-14}$ In our studies, the mean correction of deviation was $41.3 \mathrm{pd}$, and $99 \%$ of patients showed improvement. Abduction deficiency improved in all patients, with a mean improvement of 59\%. Patients with sixth nerve palsy showed significantly better results in the improvement of abduction than did patients with Duane syndrome. This result has not been reported previously. By closing the distance between the transposed muscles and the LR muscle, the lateral fixation suture augments both the tonic and elastic abducting forces, which produces a net increase in abduction tone. ${ }^{7}$ We restored a useful total BSVF of $\sim 71 \%$ of normal without a loss of adduction, and the AHP was eliminated in $92 \%$ of the patients. In Foster's series, the total diplopia-free field was enlarged up to $71^{\circ}$ with no loss of adduction after augmented transposition surgery for LR palsy. ${ }^{7}$ In our series, the postoperative deviation angles and abductions were stable for the duration of the follow-up period.

Overcorrection has been reported in $0-14 \%$ of the patients who underwent augmented transposition for these two disorders. ${ }^{7,9,12-14}$ Paysee et al ${ }^{13}$ reported overcorrection in a patient $(6 \%)$ with a previous bilateral $\mathrm{MR}$ recession for abducens palsy. In the present study, no overcorrection was observed, because no patient had a previous MR recession. We performed a subsequent recession of the ipsilateral or contralateral MR muscle for undercorrected cases. Previous studies have suggested that undercorrections after augmented transpositions may be treated with Botulinum toxin to the MR or recession of the contralateral MR muscle to avoid overcorrections. ${ }^{1,7,15}$

Undercorrection has been reported in $0-25 \%$ of the patients who underwent augmented transposition for LR palsy or type 1 Duane syndrome.,12,13 In our series, $21 \%$ of the patients who had a diagnosis of sixth nerve palsy and $15 \%$ of the patients who had a diagnosis of type 1 Duane syndrome needed reoperation on the MR muscle of the same eye (after 6 months) or the opposite eye. The major advantage of augmented VRT surgery was a significant reduction in the need to weaken the ipsilateral MR muscle, as is required with most other transposition procedures, while minimizing the risk of anterior segment ischemia. Anterior segment ischemia has been reported after augmented VRT surgery. ${ }^{16}$ None of our patients experienced this complication, because we preserved at least one anterior ciliary vessel in patients who underwent surgery on three rectus muscles.

Foster ${ }^{7}$ reported that VRT with the addition of lateral fixation sutures preserved adduction by eliminating the need for additional MR recession. Our results are similar to those previously reported by Foster, ${ }^{7}$ who did not find any patient with a limitation of adduction. Some authors have observed no adduction deficiencies, 7,12,13 although other authors have reported that $13-43 \%$ of patients who underwent augmented transposition suffered a mild limitation of adduction. ${ }^{9,14}$ The occurrence of vertical deviation after augmented VRT to the LR muscle insertion was reported in $2-11 \%$ of patients. ${ }^{8,9,12,13}$ Our results were similar to those previously reported. The transposed muscles may achieve more stability if they are fixed to the sclera by posterior lateral fixation sutures, thereby avoiding side slippage during ocular rotations.

Mehendale et $a l^{17}$ used augmented temporal SR transposition with adjustable MR recession for the treatment of Duane syndrome and sixth nerve palsy. They reported that the SR transposition allowed for the option of simultaneous MR recession without greatly increasing the risk of anterior segment ischemia in patients with severe abduction limitation who require transposition surgery. ${ }^{17}$ The results of SR muscle transposition combined with $\mathrm{MR}$ recession appear to be comparable to the results of VRT with posterior augmentation for the treatment of type 1 Duane syndrome and sixth nerve palsy (Table 3). The augmented VRT surgery has been shown to enhance the abducting vector of the transposed muscles, correcting a strabismic deviation created by dysfunctional LR forces. ${ }^{18,19}$ It has been proved to have an additional beneficial advantage in that the ipsilateral MR muscle can be left unoperated, limiting the potential for anterior segment ischemia. ${ }^{7}$ The addition of an abducting force to the eye has a theoretical advantage of preventing 
Table 3 Comparison of results of vertical rectus muscle transposition with posterior augmentation and superior rectus muscle transposition, combined with medial rectus muscle recession for treatment of type 1 Duane syndrome and sixth nerve palsy

\begin{tabular}{|c|c|c|c|c|c|c|c|c|c|c|c|c|c|c|c|c|}
\hline & \multicolumn{8}{|c|}{ Duane syndrome } & \multicolumn{8}{|c|}{ Sixth Nerve Palsy } \\
\hline & \multirow{2}{*}{\multicolumn{2}{|c|}{$\begin{array}{c}\begin{array}{c}S R T+M R c \\
\text { surgery }\end{array} \\
\begin{array}{c}\text { Mehendale et al }{ }^{17} \\
(\mathrm{n}=10)\end{array}\end{array}$}} & \multicolumn{6}{|c|}{ VRT surgery with posterior augmentation } & \multirow{2}{*}{\multicolumn{2}{|c|}{$\begin{array}{c}\begin{array}{c}S R T+M R c \\
\text { surgery }\end{array} \\
\begin{array}{c}\text { Mehendale et al } \\
(\mathrm{n}=7)\end{array}\end{array}$}} & \multicolumn{6}{|c|}{$V R T$ surgery with posterior augmentation } \\
\hline & & & \multicolumn{2}{|c|}{$\begin{array}{l}\text { Rosenbaum et al }{ }^{1} \\
\quad(\mathrm{n}=42)\end{array}$} & \multicolumn{2}{|c|}{$\begin{array}{l}\text { Yazdian et al }{ }^{12} \\
\quad(\mathrm{n}=38)\end{array}$} & \multicolumn{2}{|c|}{$\begin{array}{l}\text { Akar et al } \\
(\mathrm{n}=40)\end{array}$} & & & \multicolumn{2}{|c|}{$\begin{array}{l}\text { Foster et al } \\
\quad(\mathrm{n}=7)^{\mathrm{a}}\end{array}$} & \multicolumn{2}{|c|}{$\begin{array}{l}\text { Yazdian et al }{ }^{12} \\
\quad(\mathrm{n}=24)\end{array}$} & \multicolumn{2}{|c|}{$\begin{array}{c}\text { Akar et al } \\
(\mathrm{n}=47)\end{array}$} \\
\hline & Pre-op & Post-op & Pre-op & Post-op & Pre-op & Post-op & Pre-op & Post-op & Pre-op & Post-op & Pre-op & Post-op & Pre-op & Post-op & Pre-op & Post-op \\
\hline AHP (mean, deg) & 24 & 3 & 21 & 4 & 38 & 12 & 27.5 & 3.8 & 36 & 5 & NR & NR & 24 & 7 & 25 & 1.8 \\
\hline Abduction (mean, & -4 & $-2(50)$ & -3.9 & $-2.8(28)$ & -4 & $-2(50)$ & -3.8 & $-2.2(42)$ & -4.8 & -3.0 & -5.5 & -3.6 & -4.2 & -2.3 & -3.9 & $-1.6(59)$ \\
\hline $\begin{array}{l}\text { (post-op. change (\%))) } \\
\text { Induced vertical dev. } \\
\text { (no. of pat. }(\%))\end{array}$ & - & $0(0)$ & - & $1(2)$ & - & $3(8)^{\mathrm{b}}$ & - & $4(10)^{\mathrm{c}}$ & - & $2(29)$ & - & NR & - & $0(0)$ & - & $3(6)^{c}$ \\
\hline $\begin{array}{l}\text { MR recession surgery } \\
(\text { no. of pat. }(\%))^{\mathrm{d}}\end{array}$ & & $10(100)$ & - & $6(14)$ & - & $9(24)$ & - & $6(15)$ & - & $7(100)$ & - & $2(29)$ & - & $6(25)$ & - & $10(21)$ \\
\hline Follow-up (months) & - & 8 & - & 12 & - & 18 & & 38 & - & 10 & & 12 & - & 18 & - & 37 \\
\hline
\end{tabular}

Abbreviations: AHP, abnormal head posture; deg, degree; dev, deviation; MR, medial rectus muscle; MRc, medial rectus muscle recession; pat, patients; pd, prism diopter; postop, postoperative; pre-op, preoperative; SRT, superior rectus muscle transposition; VRT, vertical rectus muscle transposition.

aIn Foster's study, 7 eyes of the 21 patients who underwent VRT surgery with posterior augmentation had unilateral sixth nerve palsy.

${ }^{\mathrm{b}}$ Two of the three patients underwent vertical muscle surgery.

${ }^{\mathrm{c}}$ All patients had $\leq 4 \mathrm{pd}$ angle-induced vertical deviation, but none required vertical muscle surgery.

dipsilateral or contralateral medial rectus recession surgery.

recurrence of esotropia over time, but the duration of follow-up (mean 9 months) in the study by Mehendale et $a l^{17}$ was not sufficient to address this question. However, in our series, the postoperative esotropia angle was stable for a mean of 38 months in the follow-up period. Similar results after augmented VRT surgery

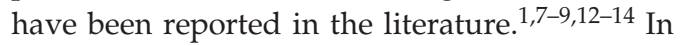
augmented VRT surgery, if the MR muscle demonstrates significant contracture on the intraoperative force duction test, additional therapy such as recession of the ipsilateral or contralateral MR muscles will be required to obtain optimal results. ${ }^{1,2,4,8}$ We performed ipsilateral or contralateral MR recession after the augmented transposition surgery in $21 \%$ of the patients who had a diagnosis of sixth nerve palsy and in $15 \%$ of the patients who had a diagnosis of type 1 Duane syndrome (for undercorrection). Mehendale et $a l^{17}$ performed ipsilateral MR recession in all cases. The amount of MR recession tends to cause a new adduction reduction. Also, Mehendale et al $^{17}$ reported a $-0.6 \mathrm{U}$ reduction in adduction after surgery. In their study, BSVF was not tested. In some series, patients who had undergone augmented transposition clearly had a useful BSVF, about $50 \%$ of normal with no loss of adduction. 1,7 Some complications after augmented VRT surgery also have been described, including unwanted vertical deviations and anterior segment ischemia. ${ }^{8,9}$ In our series, the occurrence of vertical deviation after augmented VRT was observed in $8 \%$ of patients, and these patients had $\leq 4$ pd angle-induced vertical deviation, but none required surgery. Our results are consistent with those previously reported. $8,9,12,13,20$ In the study by Mehendale et $a l^{17}$, new-onset vertical deviations (mean $10 \mathrm{pd}$ ) in the primary position were reported in two patients (12\%). The advantages of transposing the SR muscle combined with MR recession include the ability to confine surgery to only two muscles and prevent the occurrence of anterior segment ischemia. ${ }^{17}$ There is also the concern of anterior segment ischemia with an augmented VRT procedure, especially when an MR muscle recession is also required. ${ }^{16}$ Anterior segment ischemia is a risk even with two rectus muscle transposition and posterior fixation procedures. ${ }^{16,21}$ We did not encounter any anterior segment ischemia case because we preserved at least one anterior ciliary vessel in patients who underwent surgery on three rectus muscles.

A major limitation of this study is that it does not include controls. In our clinic, non-augmented transposition and/or MR recession procedures in the treatment of these cases are not preferred. Because this study was retrospective, we did not establish a control group that had the same preoperative characteristics and findings for the performance of non-augmented transposition and/or MR recession procedures for use as a comparison group.

In conclusion, VRT surgery with posterior fixation is a very effective procedure that results in improved ocular alignment and AHP, with partial restoration of abduction in patients with complete sixth nerve palsy or Duane syndrome with esotropia, AHP, and abduction deficiency. This procedure restores BSVF; however, it carries a small risk of reoperation for undercorrection and induced vertical deviation. The effect of the Foster suture did not decline over time. 


\section{Summary}

\section{What was known before}

- VRT surgery with posterior fixation is an effective treatment method for complete sixth nerve palsy and Duane syndrome with esotropia, AHP, and abduction deficiency. The effect of the Foster suture did not decline over time.

\section{What this study adds}

- The procedure carries a small risk of reoperation for undercorrection.

\section{Conflict of interest}

The authors declare no conflict of interest.

\section{References}

1 Rosenbaum AL. Costenbader lecture. The efficacy of rectus muscle transposition surgery in esotropic Duane syndrome and VI nerve palsy. J AAPOS 2004; 8: 409-419.

2 Rosenbaum AL, Foster RS, Ballard E, Rosales T, Gruenberg P, Choy A. Complete superior and inferior rectus transposition with adjustable medial rectus recession for abducens palsy. Strabismus 1984; 2: 599-605.

3 Fitzsimons R, Lee JP, Elston J. Treatment of sixty nerve palsy in adults with combined botulinum toxin chemodenervation and surgery. Ophthalmology 1988; 95: 1535-1542.

4 Mc Manaway JW, Buckley EG, Brodsky MC. Vertical rectus muscle transposition with intraoperative botulinum injection for treatment of chronic sixty nerve palsy. Graefes Arch Clin Exp Ophthalmol 1990; 228: 401-406.

5 Molarte AB, Rosenbaum AL. Vertical rectus muscle transposition surgery for Duane's syndrome. J Pediatr Ophthalmol Strabismus 1990; 27: 171-177.

6 Laby DM, Rosenbaum AL. Adjustable vertical rectus muscle transposition surgery. J Pediatr Ophthalmol Strabismus 1994; 31: 75-78

7 Foster RS. Vertical rectus transposition augmented with lateral fixation. J AAPOS 1997; 1: 20-30.

8 Velez FG, Foster RS, Rosenbaum AL. Vertical rectus muscle augmented transposition in Duane syndrome. J AAPOS 2001; 5: 105-113.
9 Britt MT, Velez FG, Velez G. Vertical rectus muscle transposition for bilateral Duane syndrome. J AAPOS 2005; 9: 416-421.

10 Flanders M, Qahtani F, Gans M, Beneish R. Vertical rectus muscle transposition and botulinum toxin for complete sixty nerve palsy. Can J Ophthalmol 2001; 36: 18-25.

11 Fiebel RM, Roper-Hall G. Evaluation of the field of binocular single vision in incomitant strabismus. Am J Ophthalmol 1974; 78: 800-805.

12 Yazdian Z, Rajabi MT, Yazdian MA, Rajabi MB, Akbari MR. Vertical rectus muscle transposition for correcting abduction deficiency in Duane's syndrome type 1 and sixty nerve palsy. J Pediatr Ophthalmol Strabismus 2010; 47: 96-100.

13 Paysse EA, Brady MKM, Ross A, Coats DK. Use of augmented rectus muscle transposition surgery for complex strabismus. Ophthalmology 2002; 109: 1309-1314.

14 Simons BD, Siatkowski RM, Neff AG. Posterior fixation suture augmentation of full-tendon vertical rectus muscle transposition for abducens palsy. J Neuroophthalmol 2000; 20: 119-122.

15 Clark RA, Rosenbaum AL, Demer JL. Magnetic resonance imaging after surgical transposition defines the anteroposterior location of the rectus muscle pulleys. $J$ AAPOS 1999; 3: 9-14.

16 Murdock TJ, Kushner BJ. Anterior segment ischemia after surgery on 2 vertical rectus muscles augmented with with lateral fixation sutures. J AAPOS 2001; 5: 323-324.

17 Mehendale RA, Dagi LR, Wu C, Ledoux D, Johnston S, Hunter DG. Superior rectus transposition and medial rectus recession for Duane syndrome and sixth nerve palsy. Arch Ophthalmol 2012; 130: 195-201.

18 Miller JM, Demer JL, Rosenbaum AL. Effect of transposition surgery on rectus muscle paths by magnetic resonance imaging. Ophthalmology 1993; 100: 475-487.

19 Clark RA, Demer JL. Rectus extraocular muscle pulley displacement after surgical transposition and posterior fixation for treatment of paralytic strabismus. Am J Ophthalmol 2002; 133: 119-128.

20 Ruth AL, Velez FG, Rosenbaum AL. Management of vertical deviations after vertical rectus transposition surgery. $J$ AAPOS 2009; 13: 16-19.

21 Simon JW, Grajny A. Anterior segment ischemia following augmented 2-muscle transposition surgery. J AAPOS 2004; 8: 586-587. 